\title{
Contribuições da Semântica Argumentativa na compreensão de questões do Enem
}

\author{
Contributions of Argumentative Semantics for \\ understanding ENEM questions
}

\section{Larissa Pontes Hübner*}

RESUMO: A principal competência usada na prova do ENEM é a compreensão leitora, buscando, portanto, destacar a leitura e a interpretação de textos variados. Suas questões são chamadas, dessa forma, de situações-problema, isto é, o estudante deve mobilizar todos os recursos que tem e tomar decisões favoráveis ao seu objetivo. Nessa perspectiva, este artigo fará uma reflexão acerca do ensino de Língua Portuguesa no Ensino Médio, partindo da análise de questões do ENEM com o propósito de testar se certas perguntas podem ser respondidas simplesmente por sua compreensão linguística, ou seja, se não seriam necessários conhecimentos prévios sobre o tema abordado. A fim de encontrar o sentido construído pelo linguístico do texto, foi utilizada como alicerce a Teoria da Argumentação na Língua (Semântica Argumentativa), de Oswald Ducrot e colaboradores, principalmente no que diz respeito à fase atual, a Teoria dos Blocos Semânticos, desenvolvida com Marion Carel. Nessa teoria, o autor postula que é o discurso que porta sentido, ou seja, para descrever o sentido devemos nos apoiar no linguístico.

PALAVRAS-CHAVES: Compreensão leitora. Ensino. ENEM.

ABSTRACT: The core competency used in ENEM is reading comprehension, so it emphasizes reading and interpretation of various texts. Thus the questions are called of problem-situations, that is, the student must mobilize all the resources he has and take decisions favorable to his goal. From this perspective, this article will make a reflection on the Portuguese Language teaching in high school, starting from ENEM questions analysis in order to test whether certain questions can be answered simply by their linguistic understanding, ie, if would not be necessary previous knowledge about the topic. To find the meaning built by text language, it was used as the foundation Argumentation Theory of Language (Argumantive Semantics), by Oswald Ducrot and collaborators, especially with regard to the current stage, the Theory of Semantic Blocks, developed with Marion Carel. In this theory, the author posits that it is the speech that has sense, that is, to describe the sense we must support in language.

KEYWORDS: Reading comprehension. Education. ENEM.

\footnotetext{
* Professora da Rede Marista de Educação, mestre em Linguística - PUCRS. E-mail: larissaphubner@gmail.com.
} 


\section{Introdução}

Temos notado que diversas provas de avaliação, nacionais e internacionais, colocam o Brasil entre os piores em educação. Essas avaliações, embora considerem as diversas áreas de conhecimento, têm como suporte uma (arqui)competência principal a ser desenvolvida: a compreensão leitora, que não só é necessária para as aulas de Língua Portuguesa, mas para todas as áreas de conhecimento.

A realidade nos mostra, no entanto, que muitos jovens estão terminando seus estudos sem terem adquirido as habilidades essenciais para compreenderem textos variados. Ademais, com a democratização do ensino superior no país, muitos desses jovens acabam entrando nas universidades sem saber ler adequadamente e, em decorrência disso, sem saber escrever uma boa redação. Um dos possíveis problemas está no método utilizado por algumas escolas no trabalho com o texto, usando-o apenas como pretexto para o ensino de gramática, da estrutura do gênero discursivo ou para discussão de um tema a fim de produzir textos. Nossa perspectiva é de que, fazendo primeiramente um trabalho focado somente no aspecto linguístico-textual para só então passar para outros aspectos, o aluno teria bases sólidas para compreender qualquer texto, pois conseguiria relacionar todos os dados apresentados discursivamente e construir o sentido expresso pelo produtor do texto.

Para se desenvolver essa ideia e encontrar o sentido construído pelo linguístico do texto, utilizamos como embasamento teórico a Teoria da Argumentação na Língua (ANL), de Oswald Ducrot e colaboradores. Nessa teoria, o autor postula que é o discurso que porta sentido, ou seja, para explicar o sentido do discurso, devemos nos apoiar nos elementos linguísticos de que ele é constituído. Salientamos que daremos enfoque maior para a fase atual da teoria, a Teoria dos Blocos Semânticos (TBS), desenvolvida com Marion Carel. Logo, ao falarmos de Semântica Argumentativa, estamos falando da teoria como um todo: desde os conceitos primários da ANL sobre a língua ser argumentativa, não informativa, até os conceitos de bloco semântico da 
TBS, passando pelas bases saussureanas e enunciativas. Por ser uma teoria que usa somente a língua para explicar o sentido do discurso, parece ser muito útil no ensino da compreensão leitora, indicando os caminhos para uma leitura atenta.

A prova do Exame Nacional do Ensino Médio (ENEM) serve justamente para avaliar o Ensino Médio no país (ou pretendia ter esse objetivo) e, por seguir os Parâmetros Curriculares Nacionais, tem como base a compreensão leitora em sua elaboração, nada mais relevante do que utilizar questões da prova como corpus de análise.

A partir desse pressuposto, faremos uma reflexão acerca do ensino da compreensão de textos nas aulas de Língua Portuguesa do Ensino Médio, partindo da análise de questões do ENEM com o propósito de mostrar que algumas perguntas podem ser respondidas somente com a leitura de seu textobase. Assim, apoiamo-nos na hipótese de que questões em que o enunciado pede a resposta em relação ao texto (perguntas que contenham: com base no texto, de acordo com o texto, entre outros) seriam consideradas relativamente fáceis, uma vez que o aluno não tem necessidade de buscar em seus conhecimentos o conteúdo ou informações para respondê-las corretamente. Dessa forma, pretendemos mostrar como é possível, com uma proposta teórico-linguística adequada, compreender textos somente a partir de seus elementos linguísticos. Esse tipo de análise implica em uma leitura mais atenta do texto, buscando compreender o sentido expresso pelo produtor do discurso e nada mais. Após essa análise de apreensão do sentido é que então o professor poderia passar para outros enfoques.

Iniciaremos, portanto, apresentando a prova do ENEM, explicando seu funcionamento e mostrando seus resultados; posteriormente falaremos sobre a compreensão leitora nos pressupostos teóricos do ENEM e nos Parâmetros Curriculares Nacionais; após, apresentaremos a teoria utilizada como alicerce em nossa pesquisa, a Semântica Argumentativa; e por fim, faremos a análise de uma questão do ENEM 2012 com o objetivo de mostrar como compreendê-la com base na teoria estudada. 


\section{A Compreensão Leitora no Enem}

O Exame Nacional do Ensino Médio (Enem) foi criado em 1998 pelo Instituto Nacional de Estudos e Pesquisas Anísio Teixeira (Inep), do Ministério da Educação, com o intuito de avaliar a qualidade do ensino médio no país.

O Novo Enem, como é chamado a partir da reformulação de 2009, contém 180 questões e uma redação, divididas em dois dias de provas. A nova proposta é estruturada a partir de uma matriz de habilidades e um conjunto de competências relacionadas a elas. A prova, a fim de aproximar-se mais do exame das Diretrizes Curriculares Nacionais e dos currículos praticados nas escolas, é decomposta em: (a) Linguagens, Códigos e suas Tecnologias (incluindo redação); (b) Ciências Humanas e suas Tecnologias; (c) Ciências da Natureza e suas Tecnologias; e (d) Matemática e suas Tecnologias.

Uma vez que os fundamentos da prova do ENEM seguem as Diretrizes Curriculares Nacionais e os Parâmetros Curriculares Nacionais para o Ensino Médio (PCNEM), falemos sobre como os PCNEM de Língua Portuguesa abordam a compreensão leitora, principalmente no que diz respeito à compreensão de textos escritos.

Os novos programas do Ensino Médio, a partir dos PCNEM (BRASIL, 1998; 2002), centram-se nos conhecimentos e nas competências essenciais e não exclusivamente no saber enciclopédico, como antigamente. Espera-se do aluno que esse saiba relacionar ideias e conceitos com situações-problemas que serão enfrentados, a fim de resolvê-los. E os PCNEM de Linguagens, Códigos e suas Tecnologias mostram, então, que se deve trabalhar as linguagens não apenas como forma de expressão e comunicação, mas como constituidoras de significados, conhecimentos e valores (BRASIL, 2002, p. 25), pois a razão principal do ato linguístico é a produção de sentido.

As competências a serem desenvolvidas foram divididas em todo o documento em três eixos estruturadores: Representação e Comunicação, Investigação e Compreensão, e Contextualização Sociocultural. Na área de 
Linguagens, Códigos e suas Tecnologias, na disciplina de Língua Portuguesa, não é diferente. Nesta pesquisa, parece-nos necessário deixar de lado o terceiro eixo, visto que comporta questões além do linguístico. Referente aos outros dois, também não nos ocuparemos de todas as competências relacionadas, porque algumas não dizem respeito diretamente à compreensão de textos, estando mais ligadas à tecnologia ou a estudos literários. Logo, o que nos importará serão as duas primeiras competências do primeiro eixo e a primeira competência do segundo eixo, visto que estas três competências estão diretamente relacionadas com a compreensão textual: (a) confrontar opiniões $e$ pontos de vista sobre as diferentes linguagens e suas manifestações específicas; (b) compreender e usar a Língua Portuguesa como língua materna, geradora de significação e integradora da organização do mundo e da própria identidade; e (c) analisar os recursos expressivos da linguagem verbal, relacionando textos/contextos, mediante a natureza, função organização, estrutura, de acordo com as condições de produção, recepção.

Sobre os procedimentos que se devem levar em conta no trabalho de leitura, os PCN+ (BRASIL, 2002) lembram quais são as maiores dificuldades que os estudantes enfrentam na compreensão textual, apresentando para essas dificuldades algumas propostas que virão de encontro com nossa perspectiva de análise, como buscar apoio no significado de palavras conhecidas e inferir o das desconhecidas; fazer relações entre os significados das palavras para construir proposições; reconhecer o que é novo e o que já está dado em cada proposição e conectar as proposições entre si; construir um significado global, a partir do entendimento da função das partes do texto (simples ou complexo; particular ou geral; relevante ou dispensável); organizar as ideias globais num esquema coerente; e articular as ideias do texto com aquilo que já se sabe (BRASIL, 2002, p. 78).

Os PCN+ (ibidem) partem de três grandes eixos para o trabalho com Língua Portuguesa; além da Competência Textual, que abrange a compreensão e a produção, também falam sobre a Competência Interativa, que no momento não nos interessará por falar de questões relativas aos sujeitos. A Competência 
Gramatical, entretanto, será de grande importância para a compreensão textual, já que algumas condutas auxiliarão nesse processo. O próprio documento ressalta (BRASIL, 2002, p. 81) que o ensino de gramática deve ser um meio, não um fim absoluto, devendo servir de recurso para chegar às outras competências. Sobre os procedimentos que nos interessam efetivamente, destacamos a coesão e a coerência, que auxiliam na construção do sentido. Ainda, as relações entre recursos expressivos, os efeitos de sentido e a construção da imagem de locutor e de interlocutor também são relevantes.

Da mesma forma, o ENEM tem a compreensão em lugar privilegiado no desenvolvimento de suas questões, trazendo sempre perguntas contextualizadas, apresentando textos de diversos gêneros e relacionando não só com o conhecimento dos alunos, mas com outras questões da prova. Esse destaque pode ser encontrado em toda sua fundamentação metodológica, que inclusive intitula o processo de arquicompetência (BRASIL, 2005, p. 59), como visto no seguinte trecho:

O ENEM assume a leitura e as leituras como pressuposto inicial e sinaliza para o trabalho sistemático com essa arquicompetência para o desenvolvimento das competências e habilidades representadas como necessárias ao final da educação básica. A avaliação da leitura está presente em toda sua plenitude seja na prova de múltipla escolha seja na produção do texto escrito. A leitura assume no ENEM os pressupostos da área Linguagens e Códigos (BRASIL, 2005, p. 59).

Com o argumento citado, compreendemos que a leitura é um pressuposto na elaboração da prova, não só na área de Linguagens, Códigos e suas Tecnologias, e, em decorrência disso, escolhemos não analisar questões dessa área específica, mas de outra, que nesse caso é a de Ciências Humanas e suas Tecnologias. Essa escolha nos permitirá mostrar o quão importante é a compreensão de textos, não só para as disciplinas de linguagem, mas para todas.

Além disso, a resolução de uma situação-problema passa obrigatoriamente pela compreensão, isto é, resolver uma situação-problema 
pressupõe compreendê-la, pois não é somente o conhecimento de mundo do sujeito que servirá para a conclusão dessa tarefa:

\begin{abstract}
Uma situação-problema, em um contexto de avaliação, define-se por uma questão que coloca um problema, ou seja, faz uma pergunta e oferece alternativas, das quais apenas uma corresponde ao que é certo quanto ao que foi enunciado. Para isso, a pessoa deve analisar o conteúdo proposto na situação-problema e recorrendo às habilidades (ler, comparar, interpretar, etc.) decidir sobre a alternativa que melhor expressa o que foi proposto (BRASIL, 2005, p. 30).
\end{abstract}

Com isso, todas as questões da prova são estruturadas de modo a verificar se o aluno é capaz ou não de ler e compreender textos em linguagens diversas identificando e selecionando informações, encontrando os implícitos e analisando os elementos de que o texto é constituído.

Por fim, falemos da Matriz de Referência para o Novo ENEM 2009 (BRASIL, 2009), documento que lista todas as competências que se espera dos candidatos que prestarão a prova. Nele, destacam-se cinco eixos cognitivos comuns a todas as áreas de conhecimento: Dominar linguagens, Compreender fenômenos, Enfrentar situações-problema, Construir argumentação e Elaborar propostas.

Apesar de todos os eixos de alguma forma estarem relacionados, nos centraremos apenas em um desses eixos cognitivos: enfrentar situaçõesproblema, pois acreditamos que, a partir dele, o estudante pode responder corretamente grande parte das questões descritas na prova. Isso porque, a partir da teoria que utilizamos, os alunos perceberão que os enunciados podem ser compreendidos pela linguagem, sem recorrer a conhecimentos prévios sobre o assunto. Pretendemos com isso que o aluno de ensino básico seja competente ao enfrentar uma situação-problema (isto é, a resolução de uma questão), analisando o texto-base, relacionando ideias, para, assim, compreender o que foi lido e assinalar a alternativa correta.

Além dos cinco eixos cognitivos, cada área pressupõe competências e habilidades. A Matriz de Referência para o Novo ENEM 2009 é estruturada em 120 competências e 30 habilidades relacionadas a elas, divididas de acordo com a área. Daremos destaque para quatro habilidades que vão ao encontro de 
nossa perspectiva. As duas primeiras estão na matriz de referência da área de Linguagens, Códigos e suas Tecnologias, na sétima competência dentre nove, intitulada Confrontar opiniões e pontos de vista sobre as diferentes linguagens e suas manifestações específicas. São elas:

H22 - Relacionar, em diferentes textos, opiniões, temas, assuntos e recursos linguísticos.

H23 - Inferir em um texto quais são os objetivos de seu produtor e quem é seu público alvo, pela análise dos procedimentos argumentativos utilizados (BRASIL, 2009).

$\mathrm{Na}$ habilidade 22, espera-se do candidato que saiba relacionar opiniões, temas, assuntos e recursos linguísticos que, como veremos mais adiante, é a base da Semântica Argumentativa, remetendo a Ferdinand de Saussure e o valor dos signos. Já na habilidade 23, almeja-se que o estudante consiga identificar os objetivos do produtor do discurso e seu público alvo, isto é, seu interlocutor, noção que também será vista nos pressupostos teóricos desta pesquisa no que diz respeito à enunciação.

A terceira habilidade a que daremos destaque está na matriz de referência da área de Ciências Humanas e suas Tecnologias, na competência 1 sobre compreender os elementos culturais que constituem as identidades: é a habilidade 4, comparar pontos de vista expressos em diferentes fontes sobre determinado aspecto da cultura. Já a quarta é a habilidade 14, comparar diferentes pontos de vista, presentes em textos analíticos e interpretativos, sobre situação ou fatos de natureza histórico-geográfica acerca das instituições sociais, políticas e econômicas (BRASIL, 2009), na competência 3, sobre a compreensão da produção e do papel histórico das instituições sociais, políticas e econômicas. Essas duas habilidades têm o mesmo objetivo: que o aluno saiba comparar e, com isso, relacionar fatos, ideias e recursos linguísticos.

De acordo com a Fundamentação Teórico-Metodológica do ENEM (BRASIL, 2005), a prova toda tem como foco central a compreensão leitora, garantindo um entorno contextualizado antes de cada questão. Dessa forma, o aluno participante necessita, além de conhecimentos sobre os conteúdos 
cobrados, forte competência em leitura. Conforme mostram os dados, no entanto, esses alunos estão longe de ter essa competência, pecando, talvez, mais pela dificuldade de compreender os enunciados do que pela falta de conhecimentos do assunto.

Embora a média geral dos participantes oriundos de escolas federais e privadas seja maior que a dos participantes de escolas estaduais, a diferença não é tão grande em todas as áreas. Há um contraste maior entre as médias da prova de Matemática e Redação, enquanto que em Linguagens e Códigos essa diferença é muito pequena, representando apenas $11 \%$ menos, assim como em Ciências Humanas e da Natureza. Percebe-se que o problema perpassa não só escolas públicas como particulares, comprovando a ineficiência do ensino no país. O que fazer para mudar essa situação? Muitos teóricos e políticos estão tentando encontrar a resposta para essa pergunta. $O$ que faz com que isso aconteça? Parece haver diversos fatores que influenciam a decadência do ensino básico. 0 desenvolvimento de competências e habilidades que envolvam a compreensão leitora pode ajudar? Definitivamente acreditamos que sim.

\section{Teoria da Argumentação na Língua}

A Teoria da Argumentação na Língua (ANL), ou Semântica Argumentativa, foi criada por Oswald Ducrot e colaboradores na École de Hautes Etudes Sociales de Paris há trinta anos. Mais tarde juntou-se a ele Marion Carel, desenvolvendo a Teoria dos Blocos Semânticos (TBS), em que afirma que o sentido de uma expressão é constituído pelos discursos que essa expressão evoca. A ANL é uma teoria que tem como objetivo explicar o sentido construído pelo linguístico no emprego da língua e não descrevê-la. Por esse motivo, a tarefa do linguista semanticista não é a de encontrar o sentido em unidades isoladas, mas a de definir seu sentido em um contexto linguísticodiscursivo, isto é, no cotexto, pelas relações de sentido estabelecidas com outras unidades da língua. Efetivamente, parece estar falando da habilidade 22 do ENEM. 
O conceito de relação utilizado pela ANL tem suporte nos estudos sobre o valor de Ferdinand de Saussure, que, a partir da publicação de seu Curso de Linguística Geral (CLG, 1916-1970), definiu a língua como objeto de estudo do linguista, passando a estudá-la de forma sincrônica, e não diacronicamente, como até então. Para Saussure (2004), a língua consiste de um conjunto de valores negativos e relativos, por isso sua existência depende de oposições, isto é, um termo isolado só adquire sentido na combinação com outros termos.

Uma questão que devemos nos fixar é que Ducrot não faz uma separação entre língua e fala, pois para ele, a língua só pode ser analisada no momento em que é utilizada na fala, isto é, em discurso. Isso não aparece explicitamente no CLG, mas é descrito nos manuscritos publicados no Brasil em 2004 com o nome de Escritos de Linguística Geral (ELG), em que Saussure coloca em uma Nota sobre o Discurso que a língua só é criada em vista do discurso (SAUSSURE, 2004, p. 237). Salienta-se, assim, que Saussure não deixou a fala de lado, apenas focou seus estudos na língua.

Uma vez que Ducrot fixou seus estudos na língua em uso, é necessário acrescentar que a ANL é também uma teoria enunciativa. Por esse motivo, a teoria prevê um locutor que produz um enunciado para um interlocutor. 0 locutor é o responsável pelo enunciado e se coloca como centro de referência ao produzir eu-aqui-agora, enquanto o interlocutor é o destinatário. Esses seres são, no entanto, apenas teóricos, discursivos, não podendo ser confundidos como pessoas reais. Enunciação, portanto, é o surgimento de um enunciado e o sentido de um enunciado é a descrição de sua enunciação (DUCROT, 1987).

Ducrot, ao dizer que a língua é argumentativa, ou seja, que ao enunciar o locutor expõe seu ponto de vista sobre o mundo, vai contra a concepção de sentido tradicional, que diz que a linguagem é expressa por aspectos objetivos (representação da realidade), subjetivos (atitude do leitor diante da realidade) e intersubjetivos (relação locutor-alocutário), em que o primeiro seria um sentido literal (denotação) e os outros dois um sentido figurado (conotação). Para o linguista, a linguagem não contém aspectos objetivos, ela não descreve a realidade, e se assim o faz, é por aspectos subjetivos e intersubjetivos. Desse 
modo, não existe um sentido literal nem um sentido figurado, como já havia afirmado Saussure (2004), pois todo sentido só existe em contexto linguístico.

Esses dois aspectos, subjetivos e intersubjetivos, são unificados e chamados valor argumentativo do enunciado, que nada mais é do que a orientação que um termo segue no discurso para a construção do sentido. Isto é, o emprego de um termo permite ou não uma certa continuação, sendo o valor argumentativo as possibilidades de continuação.

Cabe salientar, além disso, que Ducrot distingue frase e enunciado e significação e sentido. Para ele, frase é uma entidade teórica, enquanto enunciado é a realização da frase. Assim sendo, texto é uma sucessão de frases e discurso uma sucessão de enunciados. Por fim, a definição de enunciado é a de dois segmentos que só constroem um sentido combinados.

A segunda segmentação diz que significação é o valor semântico da frase e sentido é o valor semântico do enunciado. A significação é um conjunto de instruções da frase que permitem compreender o sentido do enunciado. Isto é, quando falamos, construímos enunciados e discursos, produzindo sentidos; e somente na análise linguística buscamos o sentido em frases e textos, pois são entidades fictícias.

Para a Teoria dos Blocos Semânticos (TBS), o sentido de uma expressão é dado pelos discursos argumentativos que essa expressão evoca. Esses discursos são chamados encadeamentos argumentativos e são esquematizados pela fórmula $X$ CONECTOR $Y$, ou seja, dois segmentos unidos por um conector. É preciso ressaltar que cada um dos segmentos encadeados somente forma um sentido em relação com o outro, o que a teoria denomina interdependência semântica.

Dos conectores possíveis são apenas dois: DC (donc), que liga encadeamentos normativos do tipo de portanto, então, assim; e PT (pourtant), que liga encadeamentos transgressivos do tipo de mas, no entanto, mesmo assim. Do encadeamento argumentativo normativo construímos um bloco semântico e do transgressivo construímos outro, em que $X$ contém $A$ e $Y$ contém B. A partir de A e de B construímos oito conjuntos de encadeamentos 
podendo incluir uma negação. Desses oito encadeamentos que chamamos aspectos argumentativos, formamos dois blocos distintos.

Para exemplificar, usaremos o enunciado Está frio. Quando alguém diz esse enunciado, o faz por algum motivo, porém não por qualquer motivo. Isso porque existem possibilidades de continuação (de sentido) que funcionam e outra que não. Podemos dizer está frio, por isso vou ficar na cama ou está frio, mesmo assim vou sair da cama; porém não podemos continuar dizendo está frio, por isso vou ligar o computador, uma vez que a relação feita entre esses dois enunciados não é aceita pelos falantes (a não ser que haja um contexto maior que possa explicar essa relação).

Dentro do bloco argumentativo a relação entre os aspectos pode ser descrita dessa forma (como mostra a Figura 1):

a) Reciprocidade: que pode refletir uma relação de contrariedade, ou positiva ou negativa:

-A DC B / NEG-A DC NEG-B (está frio, portanto usarei casaco/não está frio, portanto não usarei casaco)

- NEG-A PT B / A PT NEG-B (não está frio, mas usarei casaco/ está frio, mas não usarei casaco)

b) Conversão: que reflete uma oposição:

-A DC B / A PT NEG-B (está frio, então usarei casaco/está frio, mas não usarei casaco)

- NEG-A DC NEG-B / NEG-A PT B (não está frio, então não usarei casaco/ não está frio, mas usarei casaco)

c) Transposição: que reflete uma gradualidade:

- A DC B / NEG-A PT B (está frio, por isso usarei casaco/ não está frio, mas usarei casaco)

- NEG-A DC NEG-B / A PT NEG-B (não está frio, por isso não usarei casaco / está frio, mas não usarei casaco) 
Figura 1 - Quadrado argumentativo

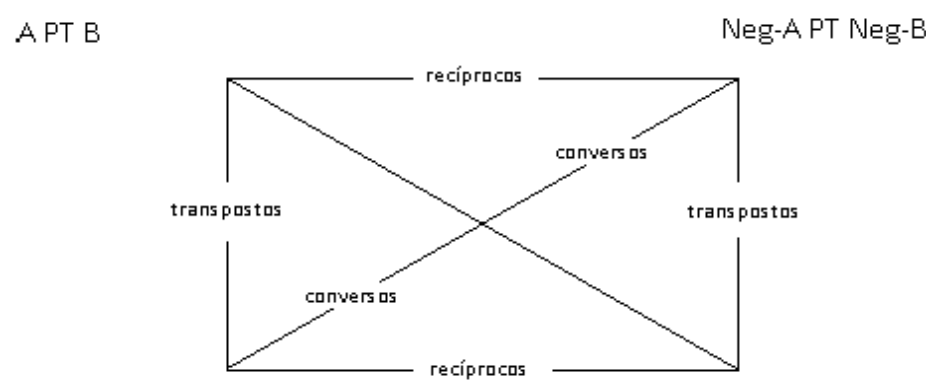

Neg-A DC B

A. DC Neg-B

Fonte: 0 autor.

Um bloco pode constituir o mesmo sentido de outro ou não, assim como pode ter algo de absurdo; ou ainda um bloco ser doxal (comum) e o outro paradoxal (fora do comum). Nos exemplos dados, temos um bloco de sentido comum, porém seria fora do comum um bloco que contenha o enunciado Está frio, portanto não usarei casaco.

Em relação às entidades linguísticas, podemos atribuir-lhes argumentações internas (AI) ou argumentações externas (AE). Segundo a teoria (CAREL; DUCROT, 2005), a AI refere-se aos aspectos aos quais os encadeamentos pertencem e que parafraseiam ou reformulam essa entidade, podendo ser estrutural ou contextual. A AI estrutural diz respeito aos encadeamentos que fazem parte da significação linguística de uma entidade e a AI contextual refere-se à situação à qual a entidade está vinculada. Um exemplo é a palavra prudente, que tem como AI o encadeamento perigo $D C$ cuidado.

A $A E$, por outra parte, refere-se aos encadeamentos em que essa entidade linguística pode ser a origem ou o término (à esquerda, se for aporte, ou à direita, se for suporte), sendo sempre em pares, um normativo e outro transgressivo. A exemplo da palavra prudente teríamos algo como prudente $D C$ não correre prudente PT correr.

Como vimos, a TBS reforça a ideia principal da ANL de que a argumentação está na língua e não na realidade do mundo, uma vez que decorre da interdependência de dois segmentos de um encadeamento 
argumentativo. A partir disso, gostaríamos de mostrar como um enunciado do ENEM pode conter a chave para a resposta da questão proposta.

\section{Metodologia e Análise}

O objetivo deste artigo é mostrar que os enunciados do ENEM podem ser compreendidos por seu aspecto linguístico a partir da Semântica Argumentativa, sem levar em consideração todo o conhecimento prévio do leitor sobre o assunto abordado na questão, admitindo-se uma leitura atenta partindo apenas dos aspectos linguísticos do texto. Para que tal objetivo seja concretizado, analisamos na dissertação "A Semântica Argumentativa como Estratégia para Compreensão de Questões do ENEM" (SILVA, 2015) dez questões da prova do ENEM de 2011 e 2012 da área de Ciência Humanas e suas Tecnologias, das quais retiramos uma para mostrar nesse artigo.

Separamos o discurso em enunciados para melhor análise, em que identificamos as argumentações internas e externas, buscando o sentido contido nos enunciados. Ao final, a partir dos Microdados do ENEM, vemos quais as alternativas foram escolhidas em cada questão, com o propósito de descobrir a porcentagem de alunos que acertou a resposta e a porcentagem que marcou a resposta errada, comparando com o resultado da análise.

A seguinte questão faz parte da prova de Ciência Humanas e suas Tecnologias do ENEM 2012 (SILVA, 2015, p. 66):

05. Fugindo à luta de classes, a nossa organização sindical tem sido um instrumento de harmonia e de cooperação entre o capital e o trabalho. Não se limitou a um sindicalismo puramente "operário", que conduziria certamente a luta contra o "patrão", como aconteceu com outros povos.

Falcão, W. Cartas Sindicais. Boletim do Ministério do Trabalho, Indústria e Comércio,

Rio de Janeiro, v. 10, n. 85, set. 1941. Adaptado.

Nesse documento oficial, à época do Estado Novo (1937-1945), é apresentada uma concepção de organização sindical que:

a) elimina os conflitos no ambiente das fábricas.

b) limita os direitos associativos do segmento patronal.

c) orienta a busca do consenso entre trabalhadores e patrões.

d) proíbe o registro de estrangeiros nas entidades profissionais do país.

e) desobriga o Estado quanto aos direitos e deveres da classe trabalhadora. 
Primeiramente vamos dividir o texto dessa questão de 2012 em duas partes para que possamos analisá-lo de forma mais simples. A partir de então, veremos quais encadeamentos e argumentações são apresentados.

(1) Fugindo à luta de classes, a nossa organização sindical tem sido um instrumento de harmonia e de cooperação entre o capital e o trabalho.

O enunciado transcrito pode ser parafraseado pelo aspecto fuga à luta de classes $D C^{1}$ harmonia e cooperação, uma vez que comunica o conteúdo fugir-à-luta-de-classes-para-buscar-harmonia-e-cooperação. No enunciado seguinte, é explicado como funciona essa consideração:

(2) Não se limitou a um sindicalismo puramente "operário", que conduziria certamente a luta contra o "patrão", como aconteceu com outros povos.

É necessário, primeiramente, buscar o sentido contido na AI de "operário", assim como de "patrão". Partiremos dos dois segmentos classe alta (no sentido de estar mais alto na hierarquia, não em relação à riqueza) e comandar, para construir um bloco. A partir disso, usaremos o aspecto negclasse alta DC neg-comandar (parafraseável por classe baixa DC obedecer) como definição (AI) de operário, assim como o seu aspecto recíproco classe alta DC comandar como definição de patrão. Por haver essa oposição na hierarquia, o mais alto contra o mais baixo, pressupõe-se que, ao dizer que o sindicato é "operário", diz-se que é contrário a "patrão", como explicado pelo enunciado (2). Esse conceito é descrito por uma AE operário DC contra $O$ patrão, que explica os aspectos Neg-sindicalismo operário $D C$ neg-contra $O$ patrão, aspecto recíproco (contrário) do pressuposto, sindicalismo operário $D C$ contra o patrão.

\footnotetext{
${ }^{1}$ portanto
} 
Com base nos encadeamentos levantados pelos dois enunciados, chegase ao aspecto que resume o trecho em seu sentido completo: Neg-sindicalismo operário DC harmonia e cooperação, que leva à conclusão: organização sindical $D C$ harmonia e cooperação, que é o argumento empregado pelo autor.

Voltamo-nos agora para a questão em si: qual a concepção de organização sindical apresentada pelo documento exposto?

Para responder, o estudante não precisa saber como o regime do Estado Novo funcionava. Nota-se que o leitor sem muita paciência irá direto para a opção da letra A (elimina os conflitos no ambiente das fábricas), porque, quando se trata de sindicatos e operários, a memória leva para o termo fábricas. No entanto, o trecho do documento não cita em nenhum momento o tipo de sindicato.

Também se elimina a opção $D$ (proíbe o registro de estrangeiros nas entidades profissionais do país) de imediato por não referir-se a questões de estrangeiros e a opção $E$ (desobriga o Estado quanto aos direitos e deveres da classe trabalhadora) por não tratar de obrigações do Estado.

Assim, sobram apenas duas opções, que respondemos facilmente depois da análise feita. Se a conclusão é a de que nossa organização sindical $D C$ harmonia e cooperação, a alternativa B (limita os direitos associativos do segmento patronal) também é eliminada por considerar que os patrões limitariam os direitos de associação (sindicalização) dos operários. Dessa maneira, a opção correta é a da letra C orienta a busca do consenso entre trabalhadores e patrões, pois há nesse sindicato harmonia e cooperação (descrita no uso da expressão consenso) entre os operários e seus patrões.

Esta questão teve um número bastante elevado de acertos, $71,10 \%$ (conforme o gráfico 1), o que confirma sua facilidade e mostra que, por mais ruim que esteja a educação no país, ainda é possível reverter a situação se os professores se dedicarem a desenvolver as competências e habilidades de que os alunos necessitam para evoluírem intelectualmente. 
Gráfico 1 - Porcentagem de escolhas por alternativa na questão

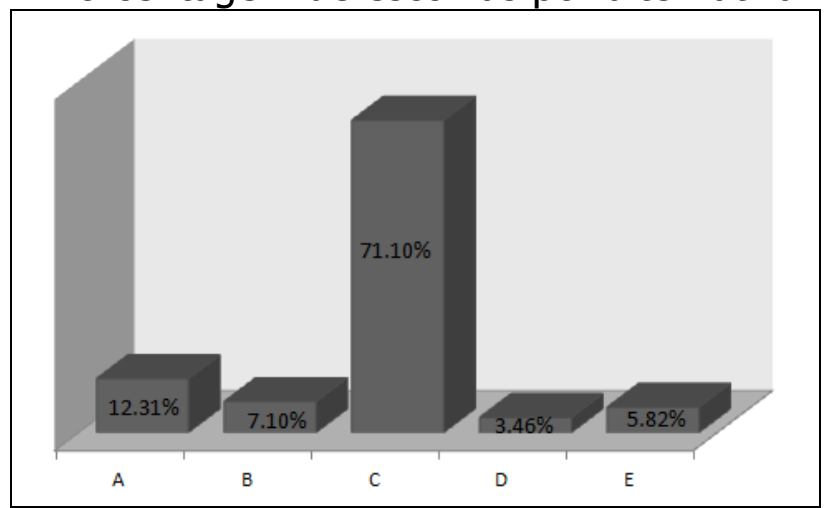

Fonte: Elaborado a partir dos microdados do ENEM 2012 (SILVA, 2015, p. 68).

Obs: os $0,21 \%$ que faltam no resultado são referentes a candidatos que não marcaram nenhuma alternativa ou mais de uma.

\section{Considerações Finais}

O propósito deste artigo foi mostrar como é possível encontrar o sentido do texto apenas por seu aspecto linguístico. Com isso, decidimos partir da análise de questões do ENEM a fim de comprovar que somente pela compreensão do texto-base é possível resolver a situação-problema proposta. Dessa forma, elegemos como teoria suporte a Semântica Argumentativa, desenvolvida por Oswald Ducrot e colaboradores, que vê o sentido do discurso sem buscar elementos externos à língua, comprovando que o sentido de uma expressão é construído pelas relações dessa expressão com outras. Porque as possibilidades de sentido são limitadas pelas relações com outros termos, isto é, pelo próprio aspecto linguístico do texto, é que nos parece tão importante utilizar a Semântica Argumentativa como suporte teórico, pois, do contrário, o leitor pode chegar a diversos sentidos, o que prejudicaria a compreensão, principalmente em uma prova de múltipla escolha.

Também é importante destacar que o uso da Semântica Argumentativa como uma teoria de leitura/compreensão leitora se dá porque ela representa uma leitura atenta dos textos. Não podemos de forma alguma afirmar que essa é a única teoria que leva à leitura atenta; pelo contrário, muitas outras teorias podem ajudar nessa tarefa. A escolha está relacionada aos conceitos 
elaborados por Oswald Ducrot, que podem auxiliar o professor no que tange ao desenvolvimento de suas próprias competências e habilidades de leitura, sendo capaz de ele próprio compreender o sentido construído pelo produtor dos textos.

Sobre os procedimentos que os PCN+ (BRASIL, 2002) propõem para os trabalhos de leitura, é importante dizer que vão ao encontro de nossa perspectiva de análise. É necessário, por exemplo, para compreender um texto de forma eficaz, apoiar-se no significado de palavras conhecidas para encontrar o sentido de outras, uma vez que os termos da língua só completam seu sentido na relação com outros termos da língua. Assim, o aluno perceberá que a falta da significação de um termo ou expressão não prejudicará o sentido global do texto. Por isso, faz-se necessário também que se relacionem as palavras, proposições, enunciados e parágrafos para atingir o sentido global, pois isoladamente as partes não formam o todo.

Sobre a proposta teórico-metodológica da prova do ENEM, parece ser bem consistente, podendo ser utilizada como base para a elaboração dos currículos escolares, mostrando na prática os conceitos dos PCN, pois tem como propósito verificar se o aluno é capaz ou não de ler e interpretar textos diversos identificando e selecionando dados, compreendendo os elementos implícitos e analisando os elementos de que o texto é constituído. Os novos programas do ensino médio, a partir dos PCN, focam em competências e habilidades fundamentais e não só no saber enciclopédico, como antigamente, por isso espera-se do aluno que esse saiba relacionar ideias e conceitos com situaçõesproblemas que serão enfrentadas a fim de resolvê-las.

A educação nacional clama por urgentes transformações, principalmente quando detectamos problemas relacionados com a competência de leitura, comprometendo o desempenho na resolução de questões que thes são propostas em diferentes avaliações. Destacamos a necessidade de implementação de novas metodologias e estratégias didáticas com foco na proficiência leitora dos jovens, pois fica evidente, depois desta pesquisa, que com o processo de ensino adequado, os alunos poderão cada vez mais 
compreender os textos lidos e dessa forma melhorar o rendimento nas provas de avaliação de ensino do país.

\section{Referências}

BRASIL. Ministério da Educação. Indicadores educacionais e dados consolidados do ENEM 2013. Disponível em: <http://download.inep.gov.br/educacao_basica/ enem/downloads/2013/indicadores_consolidados_dados_nacionais_estados_en em_2013.pdf>. Acesso em: 25 jun. 2013.

BRASIL. Ministério da Educação. Matriz de referência para o ENEM 2009. Disponível em: <http://portal.mec.gov.br/index.php?option=com_docman\&task $=$ doc_download\&gid=841\&Itemid=> Acesso em: 26 jul. 2013.

BRASIL. Ministério da Educação e do Desporto. Secretaria de Educação Fundamental. Parâmetros Curriculares Nacionais para o Ensino Médio. Brasília (DF): MEC/SEF, 1998. Disponível em: <http://portal.mec.gov.br/seb/arquivos/pdf/14_24.pdf>. Acesso em: 15 jul. 2013.

BRASIL. Ministério da Educação e do Desporto. Secretaria de Educação Fundamental. Orientações Educacionais Complementares aos Parâmetros Curriculares Nacionais (PCN+). Brasília (DF): MEC/SEF, 2002. Disponível em: <http://portal.mec.gov.br/seb/arquivos/pdf/linguagens02.pdf>. Acesso em: 23 maio 2014.

BRASIL. Ministério da Educação. Instituto Nacional de Estudos e Pesquisas Educacionais (INEP). Exame Nacional do Ensino Médio (ENEM): fundamentação teórico-metodológica. Brasília: INEP, 2005.

CAREL, Marion; DUCROT, Oswald. La Semántica argumentativa: una introducción a la teoría de los bloques semánticos. Buenos Aires: Colihue, 2005.

DUCROT, Oswald. O dizer e o dito. Tradução de Eduardo Guimarães. Campinas, SP: Pontes, 1987.

SAUSSURE, Ferdinand de. Curso de linguística geral. São Paulo: Cultrix, 1970.

SAUSSURE, Ferdinand de. Escritos de linguística geral. São Paulo: Cultrix, 2004.

SILVA, Larissa Pontes Hübner da. A semântica argumentativa como estratégia para compreensão de questões do ENEM. 2015. Dissertação (Mestrado em Letras) - Faculdade de Letras, Pontifícia Universidade Católica do Rio Grande do Sul - PUCRS, Porto Alegre, 2015. 